\title{
The role of motor evoked potentials in the management of hysterical paraplegia: case report
}

\author{
D A Jellinek FRCS, ${ }^{1}$ R Bradford MD FRCS, ${ }^{2,3}$, I Bailey FRCS, ${ }^{2}$ L Symon MD FRCS ${ }^{1}$ \\ ${ }^{1}$ Gough-Cooper Department of Neurological Surgery, Institute of Neurology, Queen \\ Square, London; ${ }^{2}$ Spinal Injuries Unit, Royal National Orthopaedic Hospital, Stanmore; \\ ${ }^{3}$ Dept Neurosurgery, Royal Free Hospital, London.
}

The role of motor evoked potentials in the management of a case of presumed hysterical paraplegia precipitated by spinal injury in a man with a previous history of surgery for scoliosis is presented. Motor evoked potentials were elicited with magnetic stimulation 12 days after injury and were within normal limits. The presence of normal motor electrophysiology and observation by the patient of involuntary movement of the lower limbs during stimulation greatly facilitated the patient's management. These findings are discussed with reference to current diagnostic investigations in the presence of a suspected diagnosis of hysterical paraplegia.

Key words: hysterical spinal paralysis; magnetic stimulation; motor evoked potentials.

\section{Introduction}

Hysterical paraplegia is a well recognised manifestation of the hallucinatory phase of 'La grande hysterie'. ${ }^{1}$ Alteration or loss of function of the lower limbs occurs in the absence of an anatomical or physiological explanation. Hysterical paraplegia is generally more common in males ${ }^{2-4}$ reversing the normal sex pattern in hysterical illness. ${ }^{5}$ This has been attributed to the relatively higher incidence of spinal trauma amongst the male population. ${ }^{2}$ The principal salient diagnostic features which make a diagnosis of functional paraplegia most likely are preservation of a normal reflex pattern, ${ }^{5}$ normal rectal sensation and a positive bulbocavernosus reflex. ${ }^{2}$ In his review of 17 cases, Apple ${ }^{2}$ considered that in the presence of normal reflex, bladder and bowel control the only initial diagnostic study is routine spinal $\mathrm{x}$-rays. We report a case where demonstration of a physiologically intact corticospinal tract with motor evoked potentials greatly facilitated patient management.

\section{Case report}

A 25 year old plumber was referred to the spinal injuries unit with acute paraplegia following a fall downstairs. Three years previously he had undergone Dubousset instrumentation and fusion for spinal scoliosis at T3-L4. Examination 24 hours after the injury demonstrated an apparent flaccid paraplegia with anaesthesia to T8. All lower limb reflexes were brisk. An indwelling catheter was present but anal tone and the cremasteric reflex were preserved. Some bizarre features were apparent on re-examination 24 hours later: intermittent recruitment of tibialis anterior on passive foot dorsiflexion, intermittent grade II activity of hip flexors and variable buttock anaesthesia. Plain $x$-rays confirmed the previous Dubousset instrumentation and fusion, there was no obvious displacement of laminal hook ends and only a few degrees of residual scoliosis.

On review of the patient's old records a similar phenomenenon was identified 4 months after the scoliosis surgery. On this occasion motor loss was less profound and the sensory changes patchy. Full recovery had occurred within days of onset. In view of this history it was felt prudent to perform spinal myelography; this failed to demonstrate any intrathecal abnormality. 
In order to clarify the patient's electrophysiological status, motor evoked potentials (MEP) were performed 11 days after admission when the patient still had an apparent flaccid paraplegia, though normal lower limb sensation and bladder function had returned. Motor potentials were obtained using transcranial magnetic stimulation with a figure of 8 coil centered on the vertex. Surface EEG electrodes were placed in a standard belly-tendon array over the first dorsal interossei muscles of the feet. The latency and amplitudes of MEP responses (Fig 1) were within the normal range. ${ }^{6}$ In addition to the electrical muscle activity, brisk lower limb contractions were noted by the patient immediately after cortical stimulation. Somatosensory evoked potentials were not investigated as the apparent neurological disturbance affected the patient's motor pathways only.

One week after motor evoked potentials had been elicited, there was a sudden (within 8 hours) complete recovery of motor and sensory function in the patient's lower limbs. Neurological examination was performed one month after discharge from the spinal injuries unit. This was normal, with complete motor power in all lower limb muscle groups, a normal reflex pattern and flexor plantar responses.

\section{Discussion}

Demonstration of functional integrity of the corticospinal tracts in the conscious subject and hence by inference of normal voluntary motor control has only been technically possible since the introduction of transcranial electrical stimulation of the motor cortex by Merton and Morton in $1980 .^{7}$ Transcranial electrical stimulation has the disadvantage of causing some scalp discomfort during the examination because of the high voltages (up to $700 \mathrm{~V}$ ) necessary for cortical stimulation, though this can to some extent be overcome with a ring cathode array. ${ }^{8}$ This has restricted its application on a widescale clinical basis. In 1985 Barker et $a l^{9}$ developed a transcranial magnetic stimulator which is capable of producing equally valuable clinical information with a relatively painless technique that is well toler-

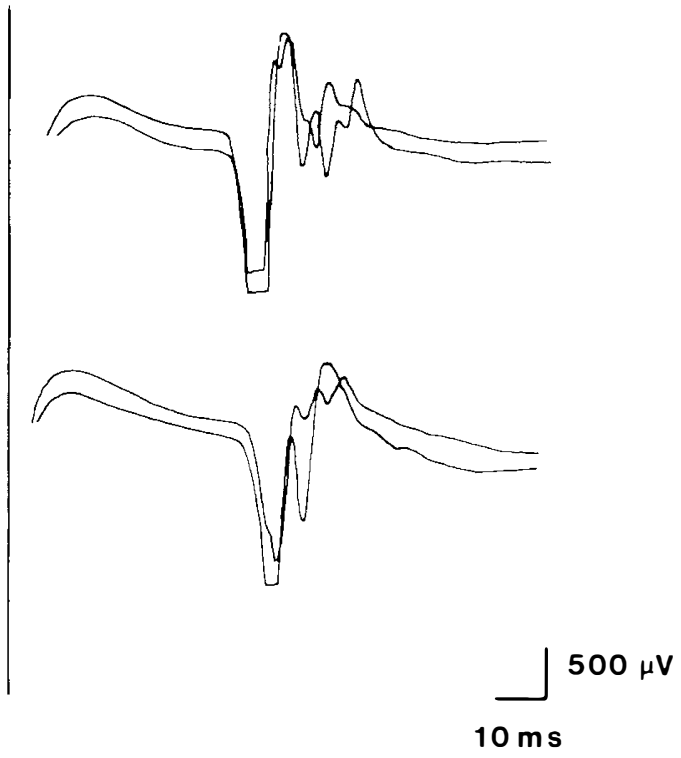

Figure 1 Motor evoked potential responses of first dorsal interosseous muscle to magnetic stimulation. Upper pair: right leg (onset latency $=43.2 \mathrm{~ms}$ ), lower pair: left leg (onset laten$\mathrm{cy}=43.2 \mathrm{~ms})$. Central conduction time (MEP latency $-\mathrm{F}$ wave latency) $=17.0 \mathrm{~ms}$ (upper range normal CTT $=17.5 \mathrm{~ms}$ ).

ated by the patient. Initial coil designs could not reliably stimulate the motor cortex beneath the vertex, limiting their application in asssesment of pathologies of the lower limbs. If a figure of 8 coil is employed (as designed in this instance by Professor Merton) then magnetic energy can be focused within the motor cortex supplying the lower limbs; this guarantees that MEPs can be recorded from the lower limbs in a normal population.

Magnetic stimulation was well tolerated by the patient described, and is under investigation as a diagnostic procedure in acute spinal trauma at the Spinal Injuries Unit, Royal National Orthopaedic Hospital, Stanmore. Further, our patient was able to witness the involuntary contraction of his leg muscles following magnetic stimulation of his head. His conviction of physiological preservation of his motor pathways was reinforced by viewing his MEP responses on the display of the recording apparatus.

The presence of normal MEPs in this patient greatly clarified his management and 
reinforced our belief in a predominatly functional element in his disease. We would recommend that MEPs are sought wherever possible in any possible case of hysterical paralysis. They are technically easy to perform, are safe ${ }^{10}$ and, as the transcranial stimulus directly discharges the motor cortex, the investigation is theoretically free from supression by voluntary control. We know of no documented case of normal MEPs in the presence of acute spinal trauma causing a motor deficit.

\section{References}

1 Critchley EMR, Canton HE (1984) Charcot's hysteria renaissant. Br Med 289: 1785-1788.

2 Apple DF (1989) Hysterical spinal paralysis. Paraplegia 27: 428-431.

3 Dickson H, Cole A, Engel S, Jones RF (1984) Conversion reaction presenting as acute spinal cord injury. Med J Aust 141: 427-429.

4 Weingarden S, Lynch C (1984) Functional paraparesis mimicking spinal cord injury resulting in admission to a spinal cord injury centre. Arch Phys Med Rehabil 65: 145-147.

5 Ziegler FJ, Imboden JB, Meyer E (1960) Contemporary conversion reactions: a clinical study. Am J Psychiatry 116: 9019.

6 Rossini PM, Distefano E, Stanzione P (1985) Nerve impulse propagation along central and peripheral fast conducting motor and sensory pathways in man. Electroencephalogr Clin Neurophysiol 60: 320-334.

7 Merton PA, Morton HB (1980) Stimulation of the cerebral cortex in the intact human subject. Nature 285: 227.

8 Rossini PM, Marciani MG, Caramia M, Roma V, Zarola F (1985) Non-invasive evaluation of input-output characteristics of sensorimotor cerebral areas in healthy humans. Electroencephalogr Clin Neurophysiol 61: 272-286.

9 Barker AT, Jalinous R, Freeston IL (1985) Non-invasive magnetic stimulation of human motor cortex. Lancet 1: 1106-1107.

10 Barker AT, Freeston IL, Jalinous R, Jarrat JA (1988) Magnetic and electrical stimulation of the brain: safety aspects. In: Rossini P, Marsden CD, eds. Non-invasive Stimulation of Brain and Spinal Cord. Alan R Liss, New York. 